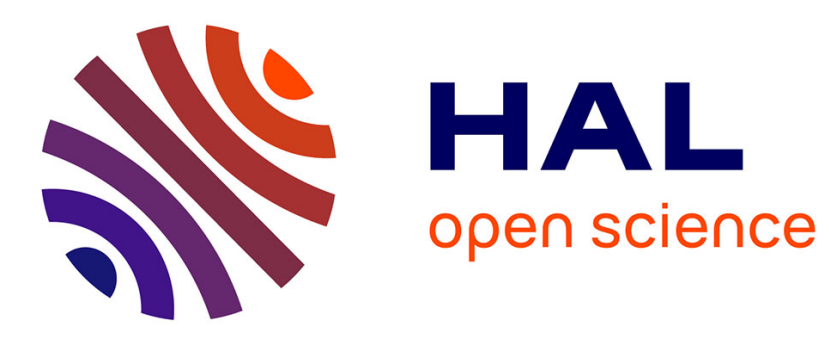

\title{
10 Years of C-K Theory: A Survey on the Academic and Industrial Impacts of a Design Theory.
}

\author{
Marine Agogué, Akin Osman Kazakçi
}

\section{To cite this version:}

Marine Agogué, Akin Osman Kazakçi. 10 Years of C-K Theory: A Survey on the Academic and Industrial Impacts of a Design Theory.. An Anthology of Theories and Models of Design: Philosophy, Approaches and Empirical Explorations, Springer, pp.219-236, 2014. hal-00983009

\section{HAL Id: hal-00983009}

https://hal-mines-paristech.archives-ouvertes.fr/hal-00983009

Submitted on 24 Apr 2014

HAL is a multi-disciplinary open access archive for the deposit and dissemination of scientific research documents, whether they are published or not. The documents may come from teaching and research institutions in France or abroad, or from public or private research centers.
L'archive ouverte pluridisciplinaire HAL, est destinée au dépôt et à la diffusion de documents scientifiques de niveau recherche, publiés ou non, émanant des établissements d'enseignement et de recherche français ou étrangers, des laboratoires publics ou privés. 


\section{0 years of $\mathrm{C}-\mathrm{K}$ theory: a survey on the academic and industrial impacts of a design theory.}

Marine Agogué, Akin Kazakçi

The goal of our research ${ }^{l}$ was to understand what is expected today from a design theory and what types of impact such type of scientific proposition may reach. To answer these questions with a grounded approach we chosed to study the developement of $C-K$ theory as phenomenon per se that can inform our research work. $C-K$ theory is clearly recognized as a design theory and it is a good representative of the level of generality and abstraction of contemporary design theory. Indeed, the validity of the theory as such has already been documented (e.g. Hatchuel \& Weil 2002, 2003, 2008, 2009; Kazakçi 2009; Reich et al 2010; Le Masson et al 2010; Ullah et al 2012). Instead the current work sets out to understand the dissemination and the impact of the theory in both academic and industrial fields. The data collection overlooks the literature on $C-K$ theory in English and in French, and includes interviews and feedbacks of students and industrial partners who applied C-K methodologies and tools. This research confirms the rapid diffusion and multiples impact of $C-K$ theory. Beyond, such study signals that there are important expectations and potential impacts of a Design Theory within the field of knowledge at large. However there are strong conditions to meet these expectations: generality, generativity, and relatedness to contemporary sciences. A similar research could be done on Nam Suh's axiomatic approach to further test these conditions. It is impossible to say what will be the next generations of Design theory but it is sure that they should progress on these directions.

1 The research presented in this chapter has benefited from a research grant given by the French government (department of Defense) and by the sponsors of the chair Theory and Methods for Innovative Design at Mines ParisTech (Dassault, RATP, Renault, SNCF, STMicroelectronics, Thalès and Vallourec). 


\section{I - Introduction: bibliometrics on C-K theory}

Over the last 10 years, Concept-Knowledge theory (or C-K theory) has gained a growing academic and industrial interest. In 2002, Hatchuel and Weil (2002) presented their first French conference paper exposing the main principles of C-K theory: this theory is based on the distinction between two expandable spaces: a space of concepts, the C-space (concepts are defined as undecidable propositions), and a space of knowledge $\mathrm{K}$. The process of design is thus defined as the co-evolution of $\mathrm{C}$ and $\mathrm{K}$ through four types of independent operators (C-C, C-K, K-C, K-K). Since the seminal English-written paper from 2003 (Hatchuel \& Weil, 2003), the features of C-K theory have been recognized as being unique for describing creative reasoning and process in engineering design, as stated by Ullah, Rashid and Tamaki (2012). Specifically, these scholars highlight the fact that one of the most noticeable features of $\mathrm{C}-\mathrm{K}$ theory is its foundation on the notion of a creative concept - a concept being an undecidable proposition with respect to the existing knowledge at the time it emerges. The impact of C-K theory is not limited to the design community: for instance, in 2012, a paper was presented in the French International Management Conference on the impact of C-K theory in management science over the last 10 years (Benguigui 2012). And today, this work echoes strongly in the industrial field: in 2010, the French company Thales, which designs systems and services for the aerospace, published a book on its design process and advocated $\mathrm{C}-\mathrm{K}$ theory as a way to organize innovative design activities (Dupas, 2010). Since 2003, the RATP, the public transport operator for the city of Paris operating the subway, has deployed C-K driven tools (Hatchuel, Le Masson \& Weil, 2009): they indeed use regularly the KCP approach, a method for collective creative design, on subjects such as "Bus Rapid Transit", "21st century Metro", "Local bus services", "Walking” or "Night bus stations".

The aim of this chapter is to grasp at the variety of impacts fostered by C-K theory in academics as well as in empirical contexts. We therefore present a survey on the impacts of the work on C-K theory in the design community as well as in other academic fields, by studying the literature on $\mathrm{C}-\mathrm{K}$ theory in English and in French. We looked at all the work done on C-K theory since its first premises in 1999: we gathered all the publications in blind peer-reviewed journals, as well as books, thesis, book chapters, conference papers with peer-reviews on abstracts and/or full papers. We analysed this material regarding different aspects: the discipline of the journal / authors, the purpose of mobilizing $\mathrm{C}-\mathrm{K}$ theory (as a theoretical framework or as an object of discussion), and the type of contributions in design theories and methods. We completed our data collection with interviews and feedbacks from 
students and practitioners who applied C-K methodologies and tools.

Since the seminal paper of Hatchuel and Weil (2002) on the foundation of a unified design theory modelling creative reasoning, over 40 papers have been published on the matter, more than 50 conference papers have been presented, 11 thesis and 5 books have built on C-K theory (cf. Fig1) ${ }^{2}$.

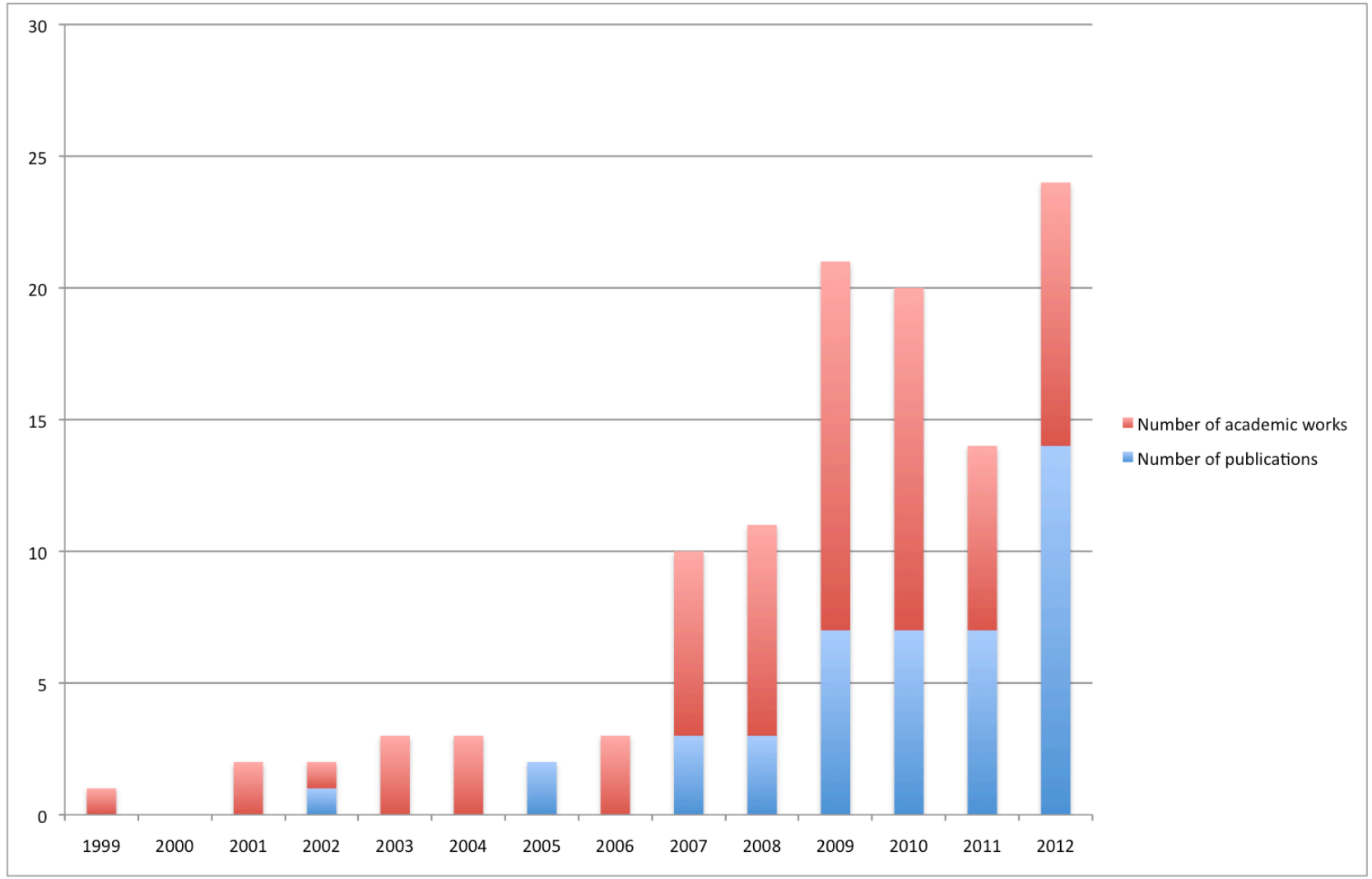

Fig1 - Evolution of the publications on C-K theory (publications $=$ in peer-review journals, works $=$ thesis, book, conference paper, book chapter)

On the 44 peer-reviewed publications around C-K theory, 13 are French-written, 12 discuss the theoretical aspects of the theory, 27 use it as a theoretical framework and 5 propose methods and tools derived from the theoretical foundations of C-K theory.

\footnotetext{
${ }^{2} \mathrm{NB}$ : Our findings are preliminary, we found 116 pieces of research around $C-K$ theory, but this survey is not exhaustive yet, as our data collection is still an on-going process, but will be over for mid-december.
} 


\begin{tabular}{|c|c|c|c|c|c|c|c|c|c|c|}
\hline Language & Type of article & 2002 & 2005 & 2007 & 2008 & 2009 & 2010 & 2011 & 2012 & Total \\
\hline \multirow[t]{3}{*}{ English } & On theoretical aspects of C-K theory & & 1 & 2 & & 1 & & 1 & 5 & 10 \\
\hline & Presenting $\mathrm{C}-\mathrm{K}$ tools and methods & & & & & 1 & 1 & & 1 & 3 \\
\hline & Using C-K theory as a theoretical framework & 1 & & 1 & 2 & 3 & 2 & 3 & 6 & 18 \\
\hline \multirow[t]{2}{*}{ French } & $\begin{array}{l}\text { On theoretical aspects of C-K theory } \\
\text { Presenting C-K tools and methods }\end{array}$ & & 1 & & & 1 & 1 & & 1 & 2 \\
\hline & Using C-K theory as a theoretical framework & & & & 1 & 1 & 3 & 3 & 1 & 9 \\
\hline \multicolumn{2}{|l|}{ Total } & 1 & 2 & 3 & 3 & 7 & 7 & 7 & 14 & 44 \\
\hline
\end{tabular}

Fig2 - Typology of peer-reviewed publication around $C$ - $K$ theory

If this stream of research initiated within the Design Theory and Methods for Innovation team at Mines ParisTech, the interest for C-K theory has now widely spread over the globe: over $40 \%$ of the academic work has been conducted outside the team of Mines ParisTech (50 academic productions out of a reported 116 in total).

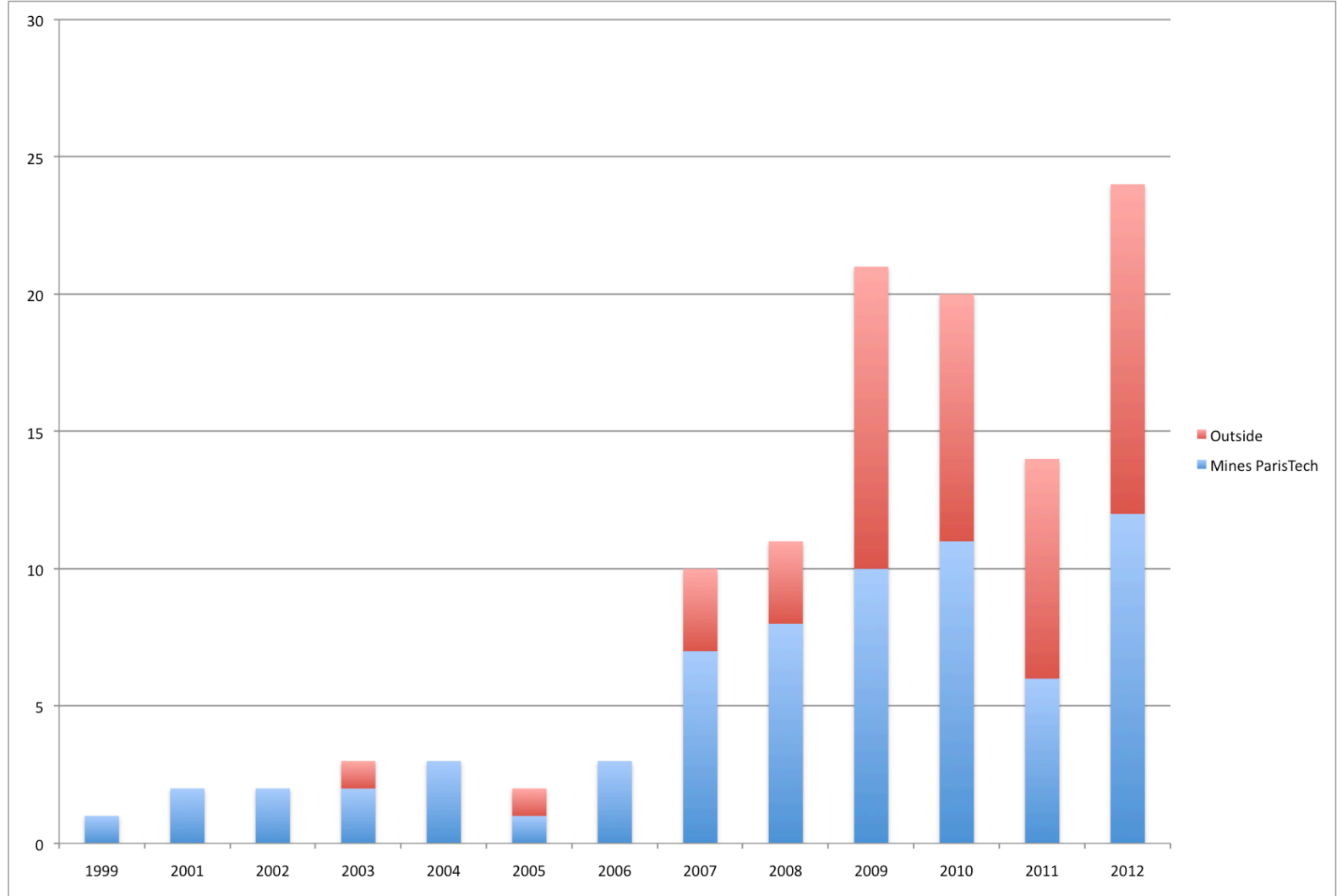

Fig2 - Expansion of the work of C-K theory outside the Design Theory and Methods for Innovation team at Mines ParisTech 


\section{II - C-K theory and engineering design theories: revitalizing a lineage of theories}

Mathematical approaches to design have been developed in the 1960s, notably by Hiroyuki Yoshikawa. They tended to model the dynamic co-evolution between design solutions and requirements. There is today a revival of work on design theory. Since the development of Yoshikawa's General Design Theory, Suh's Axiomatic Design has appeared as well as Reich and Shai' Infused Design, Braha \& Reich's Coupled Design Process and Hatchuel \& Weil's C-K theory. The Design Society, the main scientific academy in the field, announced in August 2007 the creation of a Special Interest Group on Design Theory.

Within the field of engineering design, C-K theory opens new modelling directions that explore connections with basic issues in logic and mathematics, which differs from the classic use of scientific models in design. And today, C-K theory is debated by linking its formalism with other theories. C-K theory is discussed in (Hatchuel \& Weil, 2009) regarding Coupled Design Process (Braha \& Reich, 2003), as C-K theory is used to interpret Braha and Reich's topological structures for design.

In (Shai et al, 2012), the authors present the Infused Design method to generate new concepts and methods in the classic discipline of statics, in addition to its prior use in the generation of a number of creative designs. The use of the Infused Design methodology in the creative scientific discovery process is modelled with C-K theory, leading to a deeper understanding of both Infused Design and CK theory.

In another paper published in Research in Engineering Design, Reich et al (2012) modelled a creativity method, ASIT (Horowitz 1999), with the help of C-K theory. They showed that using the modelling power of $\mathrm{C}-\mathrm{K}$ as a theory of creative design reasoning improved their understanding of existing creativity methods. Specifically, they argued: "ASIT is a specific, yet paradoxical creativity method, based on 'stay in the box' principle that seems contradictory with standard views about creativity. Modelling ASIT as a special instance of the $C-K$ theory resolved the paradox and showed that ASIT is well adapted to a class of design situations".

As stated by Hatchuel et al. (2011), " the evolution of design theories can be interpreted as an attempt to increase their generative power without endangering their robustness". Indeed, the Special Interest 
group on Design theory grounded its approach on the following idea: having a diversity of design theory allows to compare the different perspectives, as the newer theory shed new light on some theoretical assumptions of the previous one (hence the generativeness of design theories).

\section{III - C-K theory and foundational aspects of logic : unveiling design reasoning}

A central point in $\mathrm{C}-\mathrm{K}$ theory is the dependencies between what is known (and hence, what can be used as a resource for the design process) and what is yet-to-exist (a set of variants for a seed project with innovative elements). The claim of the theory is that this conceptive reasoning process is the defining essential characteristic of design and it is fundamentally different from the usual processes prevalent in formal sciences (i.e. deductive or inductive processes). Strangely, although design is a ubiquitous activity, design reasoning has not been considered per se as an object of scientific interest in traditional fields related studying reasoning processes, such as mathematics or logic. Moreover, when the need to better understand design and study associated processes formally emerged, the temptation has been to reduce or to apprehend design reasoning in terms of readily available formal constructs such as the classical logic, whose reasoning process relies on deductive operations, and machine learning, whose underlying paradigm is most of the time decision or search.

Instead of using these formal constructs and their underlying paradigm, formal research on C-K theory focused on finding or building a set of design specific models and operators describing design reasoning.

As a starting point, a suitable source of inspiration was advanced set theory (Hatchuel and Weil 1999, 2002). From a general point of view set theory can be seen as a domain where particular objects (sets) and their properties are studied by formal means. The intuition that a concept (in C-K theory) must be a different kind of set since, during design, it is not possible to be certain whether it contains any elements led to the introduction of the idea of rejecting the axiom of choice (AC) in set theory, for any modeling attempt of $\mathrm{C}$ space based on set theory: in standard set theory ZF (based on the axiomatic proposed by Zermelo-Fraenkel), the AC states that for every set there is a choice function. In C-K theory, this has been interpreted as the existence of elements are warranted for any set - which is contradictory with the intuition behind $\mathrm{C}-\mathrm{K}$ theory according to which that objects cannot be stated to 
exist during the process (or, else there is no need for design, but only for decision).

In (Hatchuel and Weil 2002), it was suggested that the axiomatic behind C space was ZF without the axiom of choice while $\mathrm{K}$ space was considered to be a CAT, the set of categories in category theory. In (Hatchuel and Weil 2003), the latter idea was abandoned and the knowledge space was defined as a space of propositions that have a logical status for some designer. The role and the implications of rejecting the axiom of choice for modelling design reasoning are explained in depth in that paper. Salustri (2003) suggested the use of action logic ALX3d, to build a formal descriptive version of C-K theory. ALX3 considers a significantly different ontology than the original formal basis of $\mathrm{C}-\mathrm{K}$ that is able to represent aspects such as the actions, preferences, beliefs, and knowledge of collaborating, imperfect agents. This allows a more specific and granular structure of knowledge. Let us note that, contrary to C-K theory, Salustri (2003, p9) sees no convincing reason to exclude axiom of choice. Instead, he states it can be used to increase flexibility of the proposed formal system.

In 2007, Hatchuel and Weil presented a new result on the theoretical foundations of C-K. They proposed a correspondence between their theory and Forcing, a method for the invention of new sets in set theory. Forcing is a technique invented by Paul Cohen in order to prove the independence of the axiom of choice from set theory. This is a two-step process. First, a generic filter G is created. The particularity of this step is that, although $\mathrm{G}$ is built using the existing sets of a given model of $\mathrm{ZF}$, it is not contained in $\mathrm{M}$ : it is a completely new object. Then, a naming process takes place where the sets in the old universe are renamed and reordered to accommodate the generic filter. The end result is a new model $\mathrm{N}$ of ZF, containing the old model $\mathrm{M}$ and the new object $\mathrm{G}$. Hatchuel and Weil argue that the correspondence with Forcing warrants and justify the properties of a design process as described by C$\mathrm{K}$ theory, providing thus a foundational basis for $\mathrm{C}-\mathrm{K}$. In their interpretation, a $\mathrm{C}-\mathrm{K}$ type reasoning process can be seen as a generalized Forcing operation on richer knowledge structures (than that of the set theory) creating at least one significantly new object while re-organizing the old objects to preserve the meaning. This works has been built upon on a recent publication in (Hatchuel, Weil, Le Masson 2012). Hatchuel (2008) gives further details on the relationship between set theory, Forcing and C-K theory. The driving theme of the presentation is the theoretical obstacles in defining a thing, which is a common issue in design as well as mathematics. From this perspective, techniques such as Forcing is interested for foundations in design theory, since they provide means for creating fundamentally new objects (with respect to what is known) in a formal way. 
Kazakci et al. (2008) suggests a new formalization of C-K theory based on Wang Algebras (Wang 1995, 1998). The logical structure underlying Wang's system is a term logic with frequency and confidence values on weak inheritance relations. In 2005, Kazakci $(2005,2007)$ makes use of this flexible and expressive language to build a design assistant based on his interpretation of $\mathrm{C}-\mathrm{K}$ type reasoning. In (Kazakci et al. 2008), the language is preserved, stripped of the memory system proposed by Wang, to propose an interpretation of the operators for $\mathrm{C}-\mathrm{K}$ theory. In this work, they also introduce a notion of models of $K$. suggesting that, based on the formalism used to represent knowledge, C-K type reasoning may take different forms. Moreover, using different knowledge structures for $\mathrm{K}$ space allows testing to what extent their underlying formalism allows a $\mathrm{C}-\mathrm{K}$ type reasoning process. Kazakci (2009) uses as a model of $\mathrm{K}$ the intuitionist logic, which is different from classical first-order logic in the interpretation of logical connectives and by the reject of the law of the excluded middle (LEM) which is a consequence of AC. Kazakci defines the concept space as a tree of formulae containing free variables and knowledge space corresponds to an incomplete theory in the logical sense. A set of operations is defined to model the progressive elaboration of the concept space, the expansion of the knowledge and the interaction of concepts and knowledge. Said in other terms, a formal interpretation of C-K theory's operators is provided the first time. The use of intuitionist logic opens the path to the investigation of the constructivist mathematics and philosophy as a basis for modeling design.

Kazakci and Hatchuel (2009) studied the intuitionist mathematics pioneered by Brouwer (Brouwer 1907, 1908). Intuitionist mathematics is one of the major constructivist approach mathematics, challenging the dominant axiomatic approach fostered especially Hilbert and several fundamental concepts in mathematics such as LEM, transfinite and actual infinity. Brouwer describes mathematics as a mental activity constructing progressively mental mathematical objects by the free choices of the mathematician - that Brouwer calls a creative subject (Kazakci and Hatchuel 2009). The free choices provide a unique mechanism inside mathematics to continue the definition (or, construction) of partially determined mathematical objects in novel and unprecedented ways, breaking away thus with any static and algorithmic descriptions. The paper opens a unique debate about the parallels between design and mathematical activity, as described by Brouwer

Hendriks and Kazakci (2010) investigated the logical implications of the dual expansion of concepts and knowledge. This property is claimed to be the main engine through which a design reasoning progress. The contribution provided is a step towards better understanding the theoretical roots of $\mathrm{C}-\mathrm{K}$ 
theory and design reasoning in general. They suggested using an extended Kripke structure by considering a partial order on what they call design stages. A design stage is a tuple $<\mathrm{K}, \mathrm{C}>$ where $\mathrm{K}$ is a partial theory representing knowledge and $\mathrm{C}$ is a (single) concept. A design stage might be extended by a design move either by expanding the concept, or by expanding the knowledge. As they discuss, this captures formally the principle of conjoint expansions of concepts and knowledge.

Going a step further, Kazakci et al. (2010) presented an investigation of C-K's formal foundations based on a simulation study. They used a graph as a minimalist knowledge structure where objects are represented by vertices and edges corresponds to the simple knowledge that the connected vertices are related in some way. They gave an interpretation of $\mathrm{C}-\mathrm{K}$ process based on this simple formalism. The presented formal model is used to conduct simulation of two contrasted design learning strategies; a concept driven strategy that is based on the concept being developed and a knowledge driven strategy that is based on learning based on the missing knowledge. They argued that the concept-strategy is much faster while the knowledge driven strategy provides a robust and well-connected knowledge space. Hendriks and Kazakci (2011) built on (Kazakci 2009; Hendriks and Kazakci 2010) to consider design as an aspect of rational agency hardly even mentioned in traditional logical theory. As an engineering discipline, design involves reasoning but seems to depend much more on a mix of factual knowledge, experimenting and imagination. They provided algorithmic descriptions of operators allowing these interactions within their logical interpretation of $\mathrm{C}-\mathrm{K}$ theory.

\section{IV - C-K theory and other disciplines: design as a form of creative rationality $^{3}$}

The impact of C-K theory goes beyond the sole domain of engineering design (cf. Fig3). It is a very strong sign of the generativeness of $\mathrm{C}-\mathrm{K}$ theory, underlining the possible to use $\mathrm{C}-\mathrm{K}$ theory as a framework to model very diverse issues.

\footnotetext{
${ }^{3}$ This part is not exhaustive, but will be enriched in the next few weeks
} 


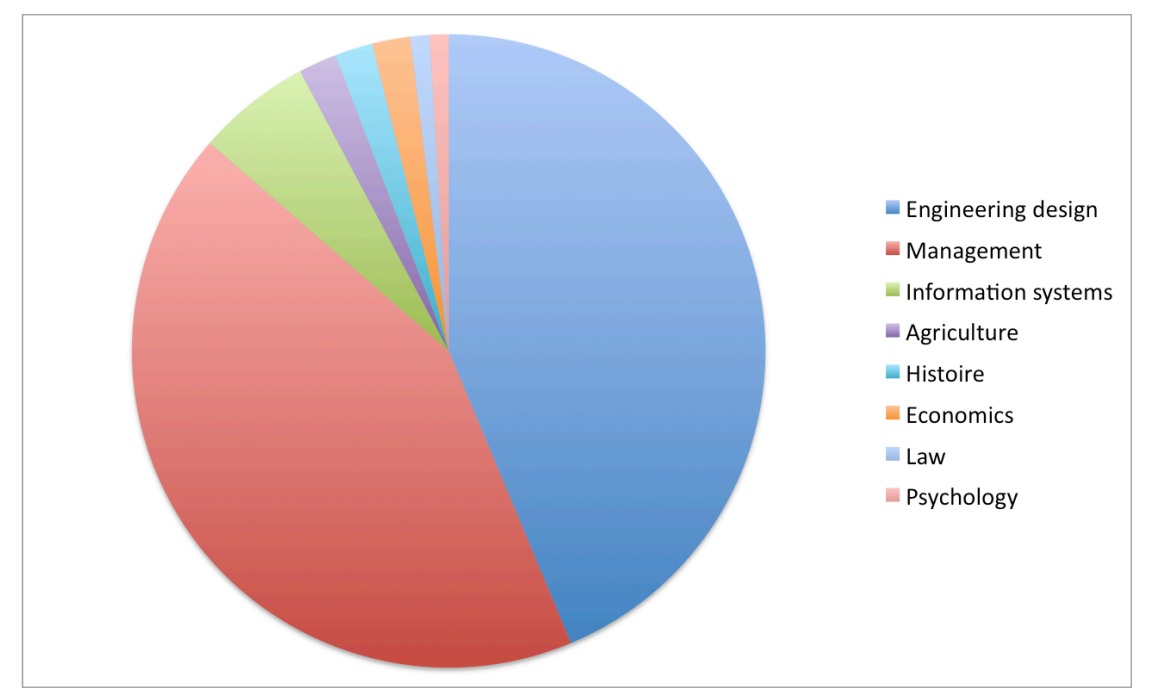

Fig3 - C-K theory in diverse fields

In the management field, the formalisms of C-K theory have been used in different settings to highlight, model, and sometimes solve managerial challenges. In his conference paper retracing the influence of C-K on management research, Benguigui (2012) stated that C-K theory is an excellent theoretical framework to explain the process of early phases of innovation, to interpret the misunderstandings (or quiproquos) in management context, to develop managerial tools and to relate the history of inventions.

C-K framework has indeed been used to build understandings of historical projects, such as the Tenerife accident (Szpirglas 2006), the Manhattan project (Lenfle 2012), the Swatch history (Garel \& Mock 2012), or the emergence of carbon markets (Cartel, Aggeri, Agogué 2012). Some scholars have proposed to build tools for radical innovation management (Hooge, Agogué, Gillier 2012; Kokshagina Le Masson Weil 2012), for building a common purpose (Gillier, 2010; Gillier \& Piat, 2011, Gillier et al 2012), for handling patent issues (Felk 2011, Felk et al 2011), or for organizing collective action in innovation activities (Elmquist \& Segrestin 2007, Béjean 2008, Arnoux, Béjean, Hatchuel 2010). Furthermore, the need to understand contemporary industrial dynamics led to mobilize C-K theorydriven diagnosis of innovative fields (Agogué, Le Masson, Robinson 2012).

The implications of C-K theory have disseminated as well in other fields, such as creativity research (Le Masson et al 2011; Hatchuel et al 2011), data mining and knowledge management (Ondrus, Pigneur 2009; Poelmans et al 2009; Goria 2009), history of engineering design (Le Masson \& Weil 2010a; 2010b), psychology and cognition (Hatchuel et al 2011; Agogué et al, 2011), ecology (Berthet, 
Bartignolle and Segrestin, 2012; Berthet et al 2012), philosophy (Schmid, 2009; Schmid, MambriniDoudet \& Hatchuel, 2011) and economics (Colasse \& Nahkla, 2011; Nahkla \& Colasse, 2011).

In the domain of cognition, Hatchuel et al. (2011) have shown how C-K theory can help overcome fixation effect, i.e. being fixed on a small number of solutions, binding creativity. They stated that the outcomes of $\mathrm{C}-\mathrm{K}$ theory based design curriculum can be measured, being a possible catalyst while teaching creative thinking to students with the ability of creative thinking. Building on the notion of fixation effect, Agogué et al (2011) claimed that there are two types of examples that C-K theory helps to characterize: (1) restrictive examples that do not change the definition or the attributes of the object, and (2) expansive examples that modify its identity by adding unexpected attributes. Using an experimental protocol, they showed in the field of cognitive psychology that the solutions proposed by the group exposed to restrictive example are less original than those given by groups exposed to expansive examples.

In ecology, a stream of research focuses on identifying and exploring effective solutions for integrating development of agriculture and conservation of biodiversity at a landscape scale. Berthet, Bartignolle and Segrestin (2012) presented a case study on an intensively farmed French cereal plain, where the reintroduction of grasslands has been proposed to protect the Little Bustard, a threatened European bird species. They analyzed the design reasoning that fostered this idea in order to highlight the innovative paths that were opened. They used C-K theory to do so, and revealed the links between the production of scientific knowledge and the generation of various solutions. It allowed them to state that specifying the ecological functions of grasslands facilitates their management.

There is today an impact of C-K theory in a branch of philosophy, called contemporary epistemology. Traditional epistemology discusses the truth or proof of truth of sciences. Contemporary epistemology is interested more in how science can create new techniques and control processes through ethics and democratic principles. Interestingly, researchers in this field have found in $\mathrm{C}-\mathrm{K}$ theory an operational framework to describe processes and principles for generic epistemologies (Schmid et al 2011). 


\section{V - Industrial applications and education: increasing needs for stimulating and teaching innovative design}

Many applications of methods and tools derived from C-K theory have been deployed and tested in diverse industrial contexts (Hatchuel, Le Masson \& Weil, 2004; Elmquist \& Segrestin, 2009; Gillier, et al 2009, Hooge, Agogué, \& Gillier (2012)). Typically, Hooge, Agogué and Gillier (2012) presented 14 industrial case studies conducted from 2009 to 2011, through an action-research methodology. Stemming from the diverse objectives that cover the innovation process, they propose practical guidelines to use $\mathrm{C}-\mathrm{K}$ theory driven tools. They suggest that such practical guidelines enable managers and designers to manage an important amount of knowledge and to structure the potential design paths of innovation projects.

Some industrial partnerships have led practitioners to present and publish vulgarization work using C$\mathrm{K}$ theory-driven methodologies and tools. In a white paper published in 2010 , the experts of the International Technological Roadmap for Semiconductors ${ }^{4}$ proposed to used $\mathrm{C}-\mathrm{K}$ methodologies to explore the potentiality of innovating beyond the "More Law" paradigm (Arden et al, 2010). In 2011, the French company Thales, which designs systems and services for the aerospace, published a book on its design process and advocated $\mathrm{C}-\mathrm{K}$ theory as a way to organize innovative design activities (Dupas, 2010). In its internal journal on Research \& Innovation, the SNCF, the French railway company, exposed their approach using $\mathrm{KCP}$, the $\mathrm{C}-\mathrm{K}$ theory-based method for collective creative design (Fontegne, 2012).

Moreover, C-K theory formalisms are taught today in various contexts (engineering schools, management schools, business schools, design curricula, entrepreneurship schools, universities) and in different countries (France, Sweden, US, Israel, Tunisia). Over the last five years, the team from Ecole des Mines de Paris has supervised closely 41 master students doing internships using C-K theory in French institutions and firms (big firms, medium size firms and start-ups). They worked in sectors such as transports, energy, food, NTIC, health, nanotechnologies and urbanism. Observations through empirical investigations (interviews with consultants specialized on $\mathrm{C}-\mathrm{K}$ methodologies, industrial partners, students) show that today, the diffusion and adoption of C-K theory through teaching and

\footnotetext{
4 a group of semiconductor industry experts representative of the sponsoring organisations based in the US, Europe, Japan, South Korea and Taiwan who intend for technology assessment only and without regard to any commercial considerations pertaining to individual products or equipment
} 
companionship leads to the emergence of practices outside of the scope of the Design Theory and Methods for Innovation team at Mines ParisTech. Those practices are indeed adapted very finely to the technological, social and organizational contexts of their applications.

\section{VI - Discussion: features of a design theory}

Studying the effects of C-K theory over the last ten years confirms the great contemporary expectations toward a design theory. First, it aims at revitalizing the knowledge accumulated in engineering design. Then, deepening the formal aspects of a design theory helps to both unveil and explain the surprises, the paradoxes, the oddness of design reasoning that goes beyond classic rationality and logics. Moreover, a design theory being a model of creative rationality, it can circulate and become a framework for disciplines outside of design, where there is a need for innovation and for building understanding on creative reasoning. A design theory therefore can become a reference model to do so. And last but not least, it is certainly not a coincidence that the rapid diffusion of C-K at least in global companies corresponds precisely to a decade where innovation has been considered as the most important competitive asset. All our interviews with sponsors showed that the most important impact of $\mathrm{C}-\mathrm{K}$ has been on the development of new radically or disruptive systems.

Like a product reveals the market, $\mathrm{C}-\mathrm{K}$ theory revealed a need to the latent need and potentials of a design theory. Yet, there is a paradox for the non-specialists: it is a difficult theory to understand but easy to practice. Of all design theories, it is the most abstract one, and understanding its foundations requires very specific high-skilled background, typically in mathematics. As for today, there is no easy software to implement $\mathrm{C}-\mathrm{K}$ theory and its development rests on the work of consultants and researchers. But in spite of these difficulties, the development of C-K theory shows three important conditions that any design theory that wants to address contemporary issues to fulfil: generality (i.e. the capacity to propose a common language on the design reasoning and design processes), generativity (i.e. the capacity to model creative reasoning and to relate to innovative engineering in all its aspects) and relatedness to contemporary knowledge and science (i.e. the capacity to relate to advances in all fields even when they seem far from the design community, such as mathematics or cognitive psychology : a design theory enables a dialogue that either benefits from or contributes to other disciplines). 
How can we test this model of three parameters of a design theory? For sure, this model would be more convincing if it was tested for instance on Nam Suh's Axiomatic Design theory, which has also a large impact. It would be interesting to compare our data with a similar approach on the developments of Axiomatic Design theory. From the perspectives of generality and generativity, we can assume that both theories have very strong features. However, it seems, but needs more confirmation, that the links between Axiomatic Design and other disciplines are narrower than those with C-K theory.

These conditions (generality, generativity and relatedness to other disciplines) are quite demanding, but they seem to be essential to ensure that a design theory has an impact, both in academia and in empirical contexts. It is impossible to say what will be the next generations of design theories but it is sure that they should progress on these directions.

Acknowledgments: We would like to thank our sponsors and industrial partners for their feedbacks on their practice with C-K theory. We would like also to thank Armand Hatchuel, Benoit Weil and Pascal Le Masson for their insights on the evolution and the dissemination of their work on $C-K$ theory. 


\section{References}

Agogué, M., Kazakçı, A.O., Weil, B., \& Cassotti, M. (2011). The impacts of examples on creative design": explaining fixation and stimulation effects, International Conference on Engineering Design, Copenhague, Aout 2011.

Agogué, M., Le Masson, P., \& Robinson, D. K. R. (2012). Orphan innovation, or when path-creation goes stale": a design framework to characterize path-dependence in real time. Techonology Analysis and Strategy Management, 24(6), pp. 603-616.

Arden, W., Brillouet, M., Cogez, P., Graef, M., Huizing, B., \& Mahnkopf, R. (2011) "More-thanMoore" White Paper, International Technological Roadmap for Semiconductors, Annual Report

Arnoux, F., Béjean, M. \& Hatchuel, A. (2010) Strategies for radical innovation: exploring the role of collaborative creative design methods, IPDM Conference, Murcia

Béjean, M. (2008). Le management des entreprises à prestations artistiques. Activités de conception, régimes de signification et potentiel de croissance. Thèse de doctorat en sciences de gestion, Paris, MINES ParisTech.

Benguigui, J-M. (2012), Les 10 ans de la théorie C-K : Revue de littérature,XXIth International French Conference on Strategic Management (AIMS), Lilles, France

Berthet, E.T.A., Bretagnolle, V. and Segrestin, B. (2012). Introduction of semi-perennial forage crops in an intensive cereal plain to restore biodiversity: a need for collective management. Journal of Sustainable Agriculture.

Berthet, E., Barnaud, C., Girard N., \& Labatut, J. (2012) Toward a reflexive framework to compare collective design methods for farming system innovation, IFSA conference 2012

Braha D, Reich Y (2003) Topological structures for modelling engineering design processes. Research in Engineering Design 14(4):185-199

Brouwer, L. E. J. (1907). Over de Grondslagen der Wiskunde [On the foundations of Mathematics], $183 p$

Brouwer, L. E. J. (1908). "De Onbetrouwbaarheid der logische principes." Tijdschrift voor 
Wijsbegeerte 2: 152-158.

Bucciarelli, L. (1988). "An ethnographic perspective on engineering design." Design Studies 9(3): 159-168.

Cartel M., Aggeri F., Agogué M. (2012) Enabling perfomativity in 'skunk labs' : the untold story of carbon markets design, EGOS Conference 2012, Helsinki

Cohen, J. P. (1963). The independance of the continuum hypothesis I. Procedings of the National Academy of Science, USA.

Cohen, J. P. (1964). The independance of the continuum hypothesis II. Procedings of the National Academy of Science, USA.

Elmquist, M., \& Segrestin, B. (2007) 'Towards a new logic for Front-End Management: from Drug Discovery to Drug Design in pharmaceutical companies', Creativity and Innovation Management Journal, Vol. 16, n², pp.106-120.

Elmquist, M., \& Segrestin, B. (2009), 'Sustainable development through innovative design: lessons from the KCP method experimented with an automotive firm', Int. Journal of Automotive Technology and Management, Vol. 9 ( $\left.{ }^{\circ} 2\right)$, pp.229-44.

Felk, Y. (2011). Evaluation et pilotage des activités de recherche pour la rupture dans la R\&D centrale de STMicroelectronics": réviser les classiques du management de la recherche industrielle. Thèse de doctorat en sciences de gestion, Paris, MINES ParisTech.

Felk, Y., Le Masson, P., Weil, B., Cogez, P., \& Hatchuel, A. (2011) Designing patent portfolio for disruptive innovation - a new methodology based on $\mathrm{C}-\mathrm{K}$ theory, International Conference on Engineering Design, Copenhague, Aout 2011.

Garel, G., Mock, E. (2012) La fabrique de l'innovation, Paris : Dunod.

Gillier, Piat, Roussel, Truchot, 2010. Managing Innovation Fields in a Cross-Industry Exploratory Partnership with C-K Design Theory, Journal of Product Innovation Management, Vol27, Num6: 883-896.

Gillier, T. (2010). Comprendre la génération des objets de coopération interentreprises par une théorie 
des co-raisonnements de conception. Thèse de doctorat en Génie des Systèmes Industriels, Grenoble, INPL

Gillier, T. and Piat, G. (2011), Exploring Over The Presumed Identity of Emerging Technology. Creativity and Innovation Management, 20: 238-252

Gillier, T., Kazakci, A.O. and Piat, G. (2012), "The Generation of Common Purpose in Innovation Partnerships: a Design Perspective," European Journal of Innovation Management, Vol. 15 No. 3

Goria, S., (2010), Proposition d'une méthode d'expression d'idées et de problèmes d'innovation, Revue ESSACHESS, 5

Hatchuel, A. (2008). Conception et Mathématiques : Essai sur le forcing en théorie des ensembles in Les nouveaux régimes de la conception : Langages, théories, métiers, (eds) Hatchuel A., \& Weil, B.

Hatchuel, A., Le Masson, P., \& Weil, B. (2012) Towards an ontology of design: lessons from C-K design theory and Forcing, Research in Engineering Design

Hatchuel, A., Le Masson, P., \& Weil, B. (2011). Teaching Innovative Design Reasoning: How C-K Theory Can Help to Overcome Fixation Effect. Artificial Intelligence for Engineering Design, Analysis and Manufacturing, 25(1), pp. 77-92.

Hatchuel, A., Reich, Y., Le Masson, P., \& Weil, B. (2011) A systematic approach of design theories using generativeness and robustness, International Conference on Engineering Design, Copenhague, Aout 2011.

Hatchuel, A. and B. Weil (1999). Pour une théorie unifiée de la conception, Axiomatiques et processus collectifs. CGS Ecole des Mines, GIS cognition-CNRS.

Hatchuel, A. \& Weil, B. (2002). C-K Theory : Notions and applications of a unified design theory, Herbert Simon International Conference on "Design Science", Lyon (France), 15th-16th March

Hatchuel, A. et Weil, B. (2003). A new approach of innovative design: an introduction to CK theory, XIVth International Conference on Engineering Design, Stockholm, Sweden, 19th-21st August.

Hatchuel, A. et Weil, B. (2007). Design as forcing : Deepening the foundations of $C-K$ theory. XVIth International Conference on Engineering Design, Paris, 28th-31th August. 
Hatchuel, A. et Weil, B. (2008). Entre concepts et connaissances: éléments d'une théorie de la conception, in Les nouveaux régimes de la conception : Langages, théories, métiers, sous la direction d'A. Hatchuel et B. Weil, Vuibert, Cerisy, Paris, pp. 115-131.

Hatchuel, A., \& Weil, B. (2009). C-K design theory: An advanced formulation. Research in Engineering Design, 19, pp. 181-192.

Hendriks, L. and A. Kazakci (2010). A formal account of the dual expansion of concepts and knowledge in C-K theory. International Deisgn Conference - Design 2010, Dubrovnik - Croatia, May

Hendriks, L. and A. Kazakci (2011). Design as Imagining Future Knowledge, a Formal Account. Logic and Interactive Rationality, (ed) Grossi, D., Minica, S., Rodenhauser, B., Smets, S., Yearbook 2010. pp111-126.

Hendriks, L., Kazakci, A., A design assistant architecture based on design tableaux, Accepted to International Design Conference, Dubrovnik, Croatia (21-24 may 2012).

Hendriks, L. and Kazakci, A., A method for design reasoning using logic: from semantic tableaux to design tableaux. ICED, Proceedings of the 18th International Conference on Engineering Design (ICED11), Vol. 2, Eds: Culley, S.J.; Hicks, B.J.; McAloone, T.C.; Howard, T.J. \& Reich, Y., p275286, 2011.

Hooge, S., Agogué, M., \& Gillier, T. (2012). A new methodology for advanced engineering design : lessons from experimenting C-K theory-driven tools. Design Society Conference 2012, Dubrovnik.

Kazakci, A. (2009). A formalisation of CK design theory based on Intuitionist Logic. International Conference on Research into Design. ICORD09. A. Chakrabarti. Banglore, India, Research Publising Services: 499-507.

Kazakci, A. and A. Hatchuel (2009). Is "creative subject" of Brouwer a designer? - an Analysis of Intuitionistic Mathematics from the Viewpoint of C-K Design Theory., International Conference on Engineering Design, ICED'09, , Stanford CA.

Kazakci, A., A. Hatchuel, P. Le Masson and B. Weil (2010). Simulation of Design reasoning based on C-K theory: a model and an example application. International Design Conference - Design 2010. Dubrovnik - Croatia. 
Kazakci, A., A. Hatchuel and B. Weil (2008). A model of C-K design theory based on a term logic: a formal background for a class of design assistants. International Design Conference 2008, Dubrovnik, Croatia.

Kazakçi, A.O., \& Tsoukias, A. (2005). Extending the C-K design theory : a theoretical background for personal design assistants. Journal of Engineering Design, 16(4), pp. 399-411.

Kokshagina, O., Le Masson, P., Weil, B., \& Cogez, P. (2012). "Risk Management Strategies in a highly uncertain environment: understanding the role of common unknown." International Product Development Management Conference, Manchester, UK, 25.

Le Masson, P., Weil, B., \& Hatchuel, A. (2006). Les processus d'innovation. Conception innovante et croissance des entreprises, Paris: Hermès.

Le Masson, P., Weil, B., \& Hatchuel, A. (2010). Strategic Management of Design and Innovation. Cambridge: Cambridge University Press

Le Masson, P., et Weil, B. (2010a), La conception innovante comme mode d'extension et de régénération de la conception réglée : les expériences oubliées aux origines des Bureaux d'études, Entreprises et histoire, $58: 1,51-73$.

Le Masson, P., et Weil, B. (2010b), Aux sources de la R\&D : genèse des théories de la conception réglée en Allemagne (1840-1960), Entreprises et histoire, 58 : 1, 11-50.

Lenfle, S. (2012) Exploration, project evaluation and design theory: a rereading of the Manhattan case, International Journal of Managing Projects in Business

Nahkla, M. \& Colasse, S., (2011), Les démarches de contractualisation comme processus de conception, Revue Politiques et Management Public

Ondrus, J., \& Pigneur, Y. (2009) C-K design theory for information systems research, 4th International Conference on Design Science Research in Information Systems and Technology, New York

Poelmans, J., Elzinga, P., Viaene, S., Dedene, G. (2009). A Case of Using Formal Concept Analysis in Combination with Emergent Self Organizing Maps for Detecting Domestic Violence, Advances in Data Mining. Applications and Theoretical Aspects, Volume 5633, 2009, pp 247-260 
Reich, Y., Hatchuel, A., Shai, O., \& Subrahamanian, S. (2012) A theoretical analysis of creativity methods inengineering design: casting and improving ASIT withinC-K theory, Research in Engineering Design

Scmid, A.-F., (2009), Les sciences de l'ingénieur entre modélisation et conception, Primeras Jornadas interdisciplinarias del Universidad del Nord-Este

Schön, D. A. (1983). The Reflective Practitioner. New York, Basic Books.

Shai, O., Reich, Y., Hatchuel, A., \& Subrahamanian, S. (2012), Creativity and scientific discovery with infused design and its analysis with $\mathrm{C}-\mathrm{K}$ theory, Research in Engineering Design,

Sharif Ullah, A.M.M., Rashid, M.M. \& Tamaki, J., (2012) On Some Unique Features of C-K Theory of Design, CIRP Journal of Manufacturing Science and Technology

Szpirglas, M. (2006), Gestion des risques et quiproquos, Revue française de gestion, $161: 2,67-88$.

Wang, P. (1995). Non-axiomatic reasoning system: Exploring the essence of intelligence PhD Thesis, Indiana University.

Wang, P. (1998). Grounding the meaning of symbols on the system's experience. Working Notes of the AAAI Workshop on the Grounding of Word Meaning: Data and Models, Madison, Wisconsin. 